\title{
Stage IIA Small Intestinal Adenocarcinoma AJCC v8
}

National Cancer Institute

\section{Source}

National Cancer Institute. Stage IIA Small Intestinal Adenocarcinoma A/CC v8. NCI

Thesaurus. Code C133897.

Stage IIA includes: T3, N0, M0. T3: Tumor invading through the muscularis propria into the subserosa, or extending into nonperitonealized perimuscular tissue (mesentery or retroperitoneum) without serosal penetration. For T3 tumors, the nonperitonealized perimuscular tissue is, for the jejunum and ileum, part of the mesentery and, for the duodenum in areas where serosa is lacking, part of the interface with the pancreas. N0: No regional lymph node metastasis. M0: No distant metastasis. (AJCC 8th ed.) 